\title{
CONSIDERACIONES FINALES
}

Tras haber completado el recorrido propuesto en esta investigación, se ha evidenciado que hablar o escribir sobre infancia no es una cuestión fácil; comprometerse a trabajar con el doble estatus de esta como sujeto y objeto de investigación, en ocasiones desborda los intereses declarados y genera preguntas que se deben asumir desde otras ópticas y con diseños metodológicos diferentes; como ejemplo, se releva el caso de la infancia infractora que requiere de un acompañamiento jurídico, la infancia étnica desde la antropología, o, la infancia regional desde informantes clave de las ciencias sociales. 
A esta complejidad, se suma el hablar de cinematografía, ya que enfrenta el reto de abordar el análisis desde diferentes perspectivas teóricas que generan una autopoiesis entre el signo y el significado. Descifrar la multiplicidad en las interpretaciones de la realidad por la que pasan los procesos de producción conciben en múltiples ocasiones el minimalismo a la hora de tomar postura frente a las preguntas generadas por la veracidad de la realidad o la ficción de los hechos, o, sobre el poder de la interpretación en manos de determinados realizadores; en este caso, es interesante indicar que la profesionalización del campo audiovisual ha jugado un papel importante para mejorar las tramas discursivas frente a los documentos fílmicos no solo en el campo de la dramaturgia sino en los pasos previos de la realización (guiones basados en becas de formación, producción a partir de estímulos del estado) que hacen que la óptica cambie las intencionalidades de comunicar hechos o historias de la región-país.

Paulatinamente, este panorama ha dotado al cine colombiano de nuevas formas de presentar narrativas que van de lo empírico a lo conceptual; muchas obras que datan de los inicios de la cinematografía en el país documentalizan de manera plana la realidad que capturaban las cámaras, aspectos que en la actualidad por vías de la tecnología y de la profesionalización del sector han forjado retos para la interpretación de sonidos diversos, palabras, dialectos textos escritos e imágenes que buscan concretarse por un lado, en un documento y testimonio de espacioso vivencias colectivas.
La manifestación de la manera en cómo los creadores cinematográficos ofrecen experiencias artísticas por medio de la narración ha emplazado la proyección de la condición infantil a instituciones como la escuela y la familia visualizando cuerpos dóciles de niños sometidos al poder de los adultos.

Dicha institucionalidad de la niñez salvo el caso de la escuela o la familia; es vista desde una perspectiva de responsabilidad social donde se entrecruzan los límites entre lo público y lo privado; sin embargo, precariamente, el cine colombiano ha hecho explicita dicha relación. Esta relación debe repensarse en tanto la escuela o la familia son espacios donde los niños comparten experiencias disciplinares (en las ciencias, matemáticas o lenguaje) y de la vida social misma.

Así, en esta investigación fueron caracterizadas las imágenes de la niñez que se encuentran en las producciones cinematográficas estrenadas y cofinanciadas por el Estado colombiano en el periodo comprendido entre el año 1922-2013; que desde la observancia de la literatura especializada, se insiste en la homogenización de tendencias descriptivas que producen una minería de datos sobre los derechos fundamentales de los sujetos y sus etapas de desarrollo biológicos. En este particular, el interés se afianzó en revisitar cómo la infancia se está reorganizando discursivamente a partir del relevamiento de campos semánticos y mediáticos en donde la imagen del niño es permeable y cambiante por las condiciones económico-temporales de un determinado espacio
La conjunción entre infancia, comunicación y cultura; permitió evidenciar el desplazamiento de discursos emergentes acerca de:

- La pérdida de la inocencia de los sujetos clásicos a través de la simulación en contextos hiper-sexualizados y los consumos creativos (danza, música, el vestuario); los cuales desde sus bases epistemológicas fueron enunciadas por Rousseau tiempo atrás. Sobre este hecho influyen los medios masivos, que se han convertido en una referencia clara de quién se es, o cómo llegar a ser de determinada manera.

- La mutación de nuevas estructuras sociales: las conformaciones familiares pasan de ser extensas y nucleares (padres, madre e hijos) a ser monoparentales, homoparentales, biparentales y reconstituidas; aunque en uno de los leit motiu de la cinematografía colombiana se anida justamente en la ausencia parental. Indistintamente del tipo de conformación familiar, esta representa un espacio para la reconstrucción del mundo de la vida infantil.

En este orden de ideas, la ampliación del contexto cultural está modificando la experiencia cotidiana $y$, al hacerlo, permite emerger nuevos modos de pensar antiguas nociones entre ellas el proceso de subjetivación humano. Esto lleva consigo un largo devenir que es producto de múltiples experiencias en las cuales los niños mediante prácticas situadas en contextos concretos se apropian activamente y de modo singular de contenidos "que vehiculizan un potencial de autoconstruc- 
ción y autoafirmación" (Santos, Pizzo, Krauth y otros, 2009).

- La deixis social como hecho social y cultural supone más que una filiación de subordinación familiar. Pese a que las clases adultas otorgan la capacidad de control sobre quienes define como menores de edad, el niño como sujeto reconfigura la nociones como la de ciudadanía al sobreponerse al reconocimiento personal de derechos políticos y sociales a una estancia/instancia en formación que refleja visiones compartidas de futuro: el ciudadano del mañana o el consumidor en desarrollo. En otras palabras, la visibilización del niño obedece a procesos sociales y subjetivos que a etapas de desarrollo teóricas.

Es de anotar que el cine como parte de los aparatos ideológicos del Estado (Althusser, 1988), atrapa y reproduce en el tiempo una imagen recurrente de la niñez asociada al lamento del entorno inmediato y a la pérdida de valores. Una visión apocalíptica que se alimenta constantemente en el circulo vicioso de los discursos hegemónicos que rememoran al tiempo pasado como la mejor opción. Verificar la ausencia de mínimos vitales entre los niños gamines o chircales de los años ochenta, se convierte en una proyección evolutiva de la adultez inmersa en el conflicto armado en la Colombia de finales de los años noventa e inicios del nuevo milenio que transgrede a los niños campesinos y los desplaza a la ruralidad de modo precario buscando protección estatal en instituciones centralizadas.
Las políticas sociales y culturales inmersas en las líneas argumentales del cine colombiano siempre reclaman una mayor inversión en la ciudadanía; sin embargo, exime de toda culpa a sus actores al remitir sus formas de actuar en la constitución de fueros canónigos o demagogos como: "Eso hace parte de nuestra malicia indígena"; o, "Todo puede pasar en el país del sagrado corazón de Jesús”.

En el análisis del corpus también se detectó que los individuos, son insertos en juegos de poder objetual a partir de la manipulación de artefactos; el poder de un niño radica en saber tocar un acordeón, cargar un arma, ejercer con proeza la mendicidad, desempeñarse adecuadamente como obrero o cambiar de frecuencia un canal de televisión. En este sentido, los largometrajes ficcionales construyen conocimiento sobre algo, en este caso, de la infancia, pero desvirtúan su esencia y la constituyen en un molde.

En coherencia con lo anterior, la infancia se presenta como una categoría social y como una invención discursa de los colectivos humanos que:

- No es estática, aunque las imágenes en la filmografía nacional den cuenta de ella como una etapa de preparación para la vida adulta. Los pensamientos, vivencias y actuaciones diversas plantean a sujetos que construyen y reconstruyen su mundo de la vida.

- Se debe analizar en contextos históricos específicos, porque en ellos surgen las ideas y prácticas. No debe pasar desapercibido, ya que un contexto es inseparable de contribuciones activas de los individuos, sus compañeros sociales, las tradiciones sociales y los materiales que se manejan. Desde este punto de vista, los contextos históricos no han de entenderse como algo definitivamente dado, sino que se construyen dinámicamente, mutuamente, con la actividad de los participantes.

- Se enmarcan en relaciones sociales, políticas y económicas particulares. Ellas son variables que configuran el contexto, describen y explican las características, dinámicas, estructuras y procesos de las complejas sociedades humanas.

Ahora bien, como construcción en el cine colombiano, la infancia presenta cuatro elementos para comprender sus bases:

- Síntoma del discurso: imposibilidad de nominar y crear sujetos de la misma categoría (Foucault) / cambio de temporalidades.

- Crisis de las instituciones encargadas: Habermas (1981) indica que la infancia como institución es producto de dos instituciones modernas y estatales: la escuela y la familia; sin embargo, en el recorrido realizado por la cinematografía colombiana, la calle usurpa el lugar de la escuela (como en La vendedora de rosas) y la ciudad el de la familia (como en Dos Ángeles y medio, La Playa D.C).

- Caída de los secretos y tabúes sociales: hace que el proceso de maduración sea cada vez "frio" ya que la niñez esta sobre expuesta a la sexualidad y a la violencia (vistas en El muro del silencio, Te busco, Los colores de la montaña); el mito de la pureza y de bondad de la niñez queda desvirtuada en el acceso temprano a sobre estímulos. 
- El niño como consumidor: configura la visión de una nueva economía nacional que se basa en servicios de pronto aliento a costa de la consolidación de productos. Esta idea se sostiene en que la cultura y el momento histórico actual hacen que los niños y niñas estén rodeados de ideologías que los seducen, particularmente por los medios de comunicación. Los medios están cargados de ideologías y contenidos que mantienen las posturas tradicionales, coloniales, hegemónicas y patriarcales. Así, Disney, Discovery, Cartoon Network, entre otros, brindan los conceptos, socialmente aceptados, de sujeto, belleza, política, masculinidad, feminidad y justicia (Calle, 2017).

Después de lo enunciado queda una ventana abierta para analizar la forma en que se presenta visualmente la infancia no solo en el cine colombiano ( $y$ en otro momento histórico), sino, en otros medios masivos que aportan nuevos elementos para la comprensión de su cultura visual, en tanto revelan y reactualizan aspectos no consientes e inconscientes del mundo social.

Mirar la infancia y sus relaciones consigo mismo, el tiempo y el espacio, determinan el estado en que se encuentra o se ha encontrado la sociedad. Es una mirada que puede construir y favorecer la visibilidad, el acercamiento a la realidad y el conocimiento de la situación de los "otros": niños con discapacidad, por ejemplo. El cine en su búsqueda por ayuda a formar conceptos, estudiar y conocer diferentes asuntos y materias, estimular emociones, formar opiniones, fomentar valores sociales y desarrollar o modificar actitudes sobre estos sujetos. 


\section{BIBLIOGRAFÍA}

Acosta, B. (2009). Análisis de las políticas de fomento del cine en Colombia. Tesis de pregrado. Facultad de Ciencias Políticas. Bogotá: Universidad Colegio Mayor de Nuestra Señora del Rosario.

Acosta, C. (2013). Historia de la infancia, su relación con la educación y las prácticas culturales en las familias, los cuidadores y los docentes de pre-escolar. Bogotá: Universidad Nacional de Colombia.

Althusser, L. (1988). Ideología y aparatos ideológicos del Estado. Freud y Lacan, Nueva Visión, Buenos Aires.

Álvarez, A. (2002). Los niños de la calle: Bogotá 1900-1950. Historia de la educación en Bogotá. Bogotá: IDEP.

Álzate, M. (2003). La infancia: concepciones y perspectivas. Pereira: Editorial Papiro.

Amador, J.C. (2014) Infancias, comunicación y educación: Análisis de sus mutaciones. Bogotá: Universidad Distrital Francisco José de Caldas.

Arévalo, O. (1996). Juventud y modernización tecnológica. Pasos, Número especial.

Ariès, P. (1960). El niño y la vida familiar en el Antiguo Régimen. Madrid: Taurus.

Ayala, D., Barragán, A. (2005) las experiencias límite y su relación con la enfermedad. México. Universidad Nacional Autónoma de México.

Bácares, C; Castro D. (2013). La eterna noche de las doce lunas: a propósito de sus aportes a la antropología de la infancia. Rayuela, 9, pp. 151-162
Belting, H. (2007). Antropología de la imagen. Buenos Aires: Katz Editores.

Benítez, K. (2017). "Las salas de cine registraron 61,7 millones de asistentes durante 2016". Recuperado de https://www.larepublica.co/economia/las-salas-de-cine-registraron-6 17-millones-de-asistentes-durante-2016-2555730

Bermúdez, E. (200I). Consumo cultural y representación de identidades juveniles. Ponencia presentada en el Congreso LASA celebrado en la ciudad de Washington D.C.

Bravo, C. (2010). Imaginarios sociales del mar. Una aproximación al caso de Cobquecura en el marco de la instalación del CFI Nueva Aldea. Tesis de master no publicada. Universidad de Concepción, Concepción.

Bustamante, E. (coord.). (2003). Hacia un nuevo sistema mundial de comunicación. Industrias culturales en la era digital. Barcelona: Gedisa.

Buxó, M; De Miguel, J. (1999). De la investigación audiovisual: fotografía, cine, vídeo, televisión. Barcelona: Proyecto A Ediciones.

Califano, B. (2015). Perspectivas conceptuales para el análisis del Estado y las politicas de comunicación. Austral Comunicación, 4/2, pp. 283-318.

Calle, M. (2017). El campo escolar, social y barrial, y la configuración de un nuevo modo de ser joven, a partir de los fenómenos de la violencia escolar. Doctorado interinstitucional de educación: Universidad Distrital Francisco José de Caldas.

Campoalegre, R. (2016). "Familia y escuela: desafíos sociales y políticos". Familia, escuela y desarrollo humano. Rutas de investigación educativa. 
Rosa Campoalegre Septien y otros; coordinadores. Bogotá: Universidad de la Salle y CLACSO.

Cardona, D. (2008). La vendedora de rosas de Victor Gaviria. Escuchar a los niños. La anticipación sin acción diez años después de la ruptura estética. Recuperado el 08 de mayo de 2017 de http//catedraluisalbertoalvarez. blogspot.com.co/2008/02/la-vendedora-de-rosas de-vctor-gaviria.html.

Carvalho, J. (2010). Los estudios culturales en América Latina: interculturalidad, acciones afirmativa y encuentro de saberes. Tabula Rasa No. 12. 229-25I

Castañeda, L. (2009). Agentes del sector cinematográfico y la diversidad cultural en Colombia. Nueva época, 15, pp. 143-168

Castellanos, G. (2003). Sistema jurídico de incentivos económicos a la cultura en los paises del Convenio Andrés Bello. Bogotá: Edición del Convenio Andrés Bello. Unidad Editorial.

Castro, B. (1997). La Pobreza en Colombia. 1886-1930. Estado, Iglesia y Ciudadanos. XVI Congreso Internacional de la Asociación de Estudios Latinoamericanos - LASA. Guadalajara: Universidad de Guadalajara.

Cogollo, S. (2015). Una mirada panorámica al cine colombiano. Revista Fundación Universitaria Luis Amigó, 2/2, pp. 233-238.

Cuartas, V. (2006). Diccionario económico financiero. Universidad de Medellín.

Chacón C., y Jerry J. (2015). Antropología e infancia. Reflexiones sobre los sujetos y los objetos. Cuicuilco, 22/64, pp. 133-153.

Chartier, R. (1996). El mundo como representación. Historia cultural entre práctica y representación. España: Editorial Gedisa.

Daza, C. E. (2015). La metáfora cromática en el cine de infancia: una revisión a una década largometrajes sobre niñez. Infancias Imágenes, I4 (I), pp. 59-76.

Daza, C. E. (2017). Notas visuales para comprender la infancia en el cine colombiana. Revista de cine fuera de campo, 3(I), pp. 57-70.

De Beauvoir, S. (1999). El segundo sexo. Madrid: Cátedra.
De Charras, D., Mastrini, G., Bizberge, A. (2013). Las politicas de comunicación en el siglo XXI. Buenos Aires: La Crujía.

DeMause, LL. (1991). La evolución de la infancia Historia de la infancia. Madrid: Alianza Universidad.

Departamento Administrativo Nacional de Estadísticas DANE (2009). Metodología encuesta de consumo cultural. (2009). Colección Documentos, núm. 71 .

Díaz, J., y Hamman. (2012). Una mirada al cine colombiano. Razón y palabra, 78.

Durand, G. (2005). Las estructuras antropológicas del imaginario. Madrid: Fondo de Cultura Económica de España.

Figueroa, C. (2016). ¿Ciudadanía de la niñez? Hallazgos de investigación sobre el movimiento por una cultura de derechos de la niñez y adolescencia en Chile. Última década, 45, pp. 118-139.

Foucault, M. (1979). La arqueología del saber. México: Siglo XXI Editores.

Foucault, M. (2000). Los anormales. Buenos Aires: Fondo de Cultura Económica.

Gaitán, L. (1999a). Bienestar social e infancia: la distribución generacional de los recursos sociales. Intervención Psicosocial, 8/3, pp. 331-348

Gaitán, L. (1999b). El espacio social de la infancia. Los niños en el Estado de Bienestar. Madrid: Comunidad de Madrid-Conserjería de Sanidad y Servicios Sociales.

Goetz, J. y LeCompte, M. (1988). Etnografía y diseño cualitativo en investigación educativa. Madrid: Ed Morata.

González, L., Barnes, C., y Borello, J. (2014). El talón de Aquiles: exhibición y distribución de cine en la Argentina. Buenos Aires: No indica.

Goyeneche, E. (2012). Las relaciones entre cine, cultura e historia: una perspectiva de la investigación audiovisual. Palabra Clave, 15/3, pp. 387-4I4 
Habermas, J. (2005). Teoría de la Acción Comunicativa II. Crítica a la razón funcionalista (M. Jiménez Redondo, Trad.). México: Taurus.

Habermas, J. (1981). Historia y crítica de la opinión pública. La transformación estructural de la vida pública. Barcelona: G. Gili.

Hall, S. (2013). El espectáculo del Otro. Eduardo Restrepo, Catherine Walsh y Víctor Vich (Comp.) Sin garantías. Trayectorias y problemáticas en estudios culturales. Ecuador: Corporación editora nacional.

Hernández, R., Fernández, C., y Baptista, L. (2004). Metodología de la investigación. México: McGraw Hill.

Herrera, C. (2013). Imaginarios sociales acerca de la infancia: una mirada desde las politicas y programas sociales de infancia de Concepción, Chile. Chile: Universidad de Concepción.

Jameson, F. (2002). El giro cultural: escritos seleccionados sobre el posmodernismo. Buenos Aires: Manantial.

Jaramillo, P. (2006). Pobreza rural en Colombia. Revista Colombiana de Sociología, 27, pp. 47-62.

Jay, M. (2003). Campos de fuerza. Entre la historia intelectual y la crítica cultural. Regímenes escópicos de la modernidad. Buenos Aires: Paidós.

Jiménez, A. (2013). Infancia. Rupturas y discontinuidades de su historia en Colombia. Bogotá: ECOE Ediciones.

Jodelet, D. (1984). La representación social: fenómenos, concepto y teoría, en Moscovici, S. Psicología Social II. Pensamiento y vida social. Psicología Social y problemas sociales. Barcelona-Buenos Aires-México: Paidós, pp. $469-494$.

Labate, C., Lozano, L., y Marino, S. (et al). (2013). Abordajes sobre el concepto de "Concentración". De Charras, D., Mastrini, G., Bizberge, A. (editores). Las politicas de comunicación en el siglo XXI. Buenos Aires: La Crujía.
Labrada, F. (2015). "Panorama de plataformas de distribución digital de cine VoD y sus modelos de negocio". Informe final 03. Ministerio de Cultura de Colombia. Dirección de Cinematografía.

Larrosa, J., Castro, I., y Sousa, J. (2007). Miradas cinematográficas sobre la infancia. Niños atravesando el paisaje. Argentina: Miño y Dávila editores.

LeCompte, M. (1995). Un matrimonio conveniente: diseño de investigación cualitativa y estándares para la evaluación de programas. Revista Electrónica de Investigación y Evaluación Educativa - RELIEVE. Vol. I. No. I.

Ley 814 de 2003, por la cual se dictan normas para el fomento de la actividad cinematográfica en Colombia. La Ley de Cine para todos (2004). Ministerio de Cultura y Proimágenes.

Ley General de Cultura (Ley 397 de 1997) "Lineamientos para la sostenibilidad del Plan Nacional de Cultura 2001-2010". Ministerio de Cultura.

Linares, B. y Quijano, P. (s.f). Nueva Ley para la infancia y la adolescencia en Colombia. OIM -Organización Internacional para las migraciones, Alianza por la Niñez. Recuperado el 08 de mayo de 2017 de http// www.scp. com.co/ArchivosSCP/LIA_beatriz_linares.pdf

Llobet, V. (2014). Pensar la infancia desde América Latina. Un estado de la cuestión. Buenos Aires: CLACSO.

Marino, A. (2004). Cine argentino y latinoamericano una mirada crítica. Argentina

Martino, S; Gregorini, V. (2013). Autobiografía y ficción en el cine. Letras de Hoje, 48/4, pp. 484-492.

Mateus, A. (2013). El indigena en el cine y el audiovisual colombiano: imágenes y conflictos. Medellín: La Carreta Editores.

Meraz-Arriola, G. (2010). Historia universal de la infancia. Acta pediátrica de México. Recuperado de: http://www.redalyc.org/articulo. oa? $\mathrm{id}=42364032600 \mathrm{I}$ 
Miller, T. (2003). The burning Babe: Children, Film, Narrative. And the Figures of Historical Witness, Douglas Ana et A. Vogler Thomas (editors), Witness an Memory, the discourse of trauma. New York: Routledge, pp. 207232.

Ministerio de Cultura (2015). Colombia de película. Nuestro cine para todos. Bogotá: Ministerio de Cultura.

Ministerio de Cultura. (2013). Anuario estadístico cine colombiano 2014. Bogotá: Dirección de Cinematografía.

Montana, F. (2018). Cine-infancia e historia en Latinoamérica. Tesis doctoral. Bogotá: Universidad Nacional y Université Paris-Sorbonne.

Moscovici, S. (1986). Psicología Social II. Pensamiento y vida social. Barcelona. Paídos.

Muñoz, C; Pachón X. (1988) Historia social de la infancia. Bogotá, 19001989. 7 vol., Bogotá: Fundación para la promoción de la investigación y la tecnología: Banco de la República.

Muñoz, C; Pachón, X. (1989). Gamines-testimonios. Bogotá: Carlos Valencia editores.

Muñoz, C; Pachón, X. (199I). La niñez en el siglo XX. Comienzos de siglo. Santafé de Bogotá: Editorial Planeta.

Muñoz, C; Pachón, X. (1996). La aventura infantil a mediados de siglo. Santafé de Bogotá: Editorial Planeta.

Muñoz, D. (2017). Cine, niños y educación. El niño como espectador cinematográfico. Tesis doctoral. Madrid: Universidad Complutense.

Muñoz, G. (2006). La comunicación en los mundos de vida juveniles. Ha cia una ciudadanía comunicativa. Manizales: Universidad de Manizales. CINDE.

Murillo, W. (2008). La investigación científica. Consultado el 18 de abril de 2018 de http//www.monografias.com/ trabajos/5/invest-científica/investcientífica.shtm

ONU. (1989). Convención sobre los Derechos del Niño. Resolución 44/25.
Ortega, P. (2016). "Perspectiva de cine colombiano. Desde lo estético, la producción, la distribución y la taquilla". Recuperado de http://calameo-pdf-download.abuouday.com/cgi-sys/suspendedpage.cgi?url=p2. calameo.com

Osorio, O. (2010). Realidad y cine colombiano: 1990-2009. Medellín: Universidad de Antioquia.

Pavez, I. (201 I). Migración infantil: rupturas generacionales y de género. Las niñas peruanas en Barcelona y Santiago de Chile. Tesis doctoral. Barcelona: Universidad Autónoma de Barcelona.

Pavez, I. (2012). Sociología de la infancia: las niñas y los niños como actores sociales. Revista de Sociología, 27, pp. 81-102.

Perdomo, У. (2013). Colombia un país de regiones. Recuperado el 06 de mayo de 2017 de http//www.lanacion.com.co/index.php/opinion/item/224088colombia-un-pais-de-regiones

Pérez, G. (20II). Observaciones fenomenológicas sobre la imagen. Anuario Colombiano de Fenomenología.

Pérez, G. (2013). Cine colombiano: estética, modernidad y cultura. Universidad del Cauca.

Piaget, J. (199|). Seis estudios de psicología. Barcelona: Editorial Labor.

problemas sociales. Barcelona: Ediciones Paidós.

Ramírez, J. (2012). Reflexiones sobre la imagen del cine colombiano. Razón y Palabra, 78.

Ramírez, J. (s.f). “Tres dimensiones: estética, animación y documental”. Análisis de género documental animado como propuesta en "Pequeñas voces" de Jairo Eduardo Carrillo y Oscar Andrade.

Rivera, J. (2014). ¿Va el cine colombiano hacia su madurez? Análisis de 10 años de ley de cine en Colombia. Anagramas Rumbos y Sentidos de la Comunicación, 13/25, pp. 127-144.

Rodríguez, P. ( 1994). La vida doméstica en la Colonia. Credencial Historia, 55. 
Rodríguez, P. (2000). Infancia, juventud y vejez. Las edades de la vida en la Colombia. Credencial Historia, 129.

Rodríguez, P. (2004). La familia en Colombia. En: Pablo Rodríguez (Coordinador) La familia en Iberoamérica 1550-1980. Bogotá: Ediciones del Convenio Andrés Bello. Universidad Externado de Colombia.

Rueda, J., y Chicharro, M. (2004). La representación cinematográfica: una aproximación al análisis sociohistórico. Ámbitos, 1/-12/1-2, pp. 427-450.

Santos, G., Pizzo, M., Krauth, K., y otros (2009). La relación adulto-niño y las dinámicas familiares en una investigación sobre la recepción y apropiación de mensajes massmediados. Investigación y desarrollo 17/I.

Santos, N. (2007). El imaginario cinematográfico y los regímenes de la mirada. Versión, 19, pp. 243-262

Schlenker, A. (2012). Se busca. Indagaciones sobre la figura del sicario. Quito: Universidad Andina Simón Bolívar.

Silva, J. (2010). Emergente, Dominante y Residual. Una mirada sobre la fabricación de lo popular realizada en el Nuevo Cine Chileno. AISTHESIS, 47.

Solana, P. (2017). "Medios de comunicación en Colombia: las transformaciones que hacen falta". Lanzas y letras. Recuperado de http://lanzasyletras. org/2017/10/06/medios-de-comunicacion-en-colombia-las-transformaciones-que-hacen-falta/

Tafur, J.A. (2013). Versiones, subversiones y representaciones de lo nacional en el cine colombiano. Desbordes, 4, pp. 9-18

Taylor, S. y Bogdan, R. (1986). Introducción a los métodos cualitativos de investigación. Barcelona: Paidós.

Tovar, B. (1994). La historia al final del milenio. Bogotá: Universidad Nacional de Colombia.

Ulvieri, S. (1986). Historiadores y sociólogos en busca de la infancia. Apuntes para una bibliografía razonada. Revista de Educación, 281, pp. 47-86
Van Cuilemburg, J., y McQuail, D. (2003). Cambios en el paradigma de política de medios. Hacia un nuevo paradigma de políticas de comunicación. European Journal of comunication 18/2, pp. 181-207.

Vargas, Z. (1991). La investigación participativa: Como utilizarla en orientación. Revista Educación, 15(2), pp. 103-110.

Vásquez, O. (2015). Las políticas públicas y los adolescentes en conflicto con la ley penal. Posibilidades y limites en la aplicación de la remisión fiscal en el Perú. Lima: Universidad Nacional Mayor de San Marcos.

Villasol, J. (2018). "La inocencia perdida y el cine". Amberes, revista cultural. Recuperado de http://amberesrevista.com/la-inocencia-perdida-y-el-cine/

Williams, R. (1992). Tecnologías de la comunicación e instituciones sociales. En: Raymond Williams (Ed.) Historia de la comunicación. De la imprenta hasta nuestros dias, 2. Barcelona: Bosch.

Zallo, R. (2007). La economía de la cultura (y de la comunicación) como objeto de estudio. Zer, 22, pp. 215-234.

Zambrano, I; De Cássia, R. (2014). Narrativas sobre el gamín en Colombia: nuestra novela del desprecio. Uni-pluri/versidad, 14/3, pp. 59-69. 


\section{FILMOGRAFÍA}

Acevedo, A. (director). ( 1923) La tragedia del silencio [cinta cinematográfica]. Colombia. Casa Cinematográfica Colombia.

Acosta, A. (director). (2012) El resquicio. [DVD]. Colombia. Cabecita negra Producciones.

Agresti, A. (director). (2002). El sueño de Valentín. [DVD]. Argentina.

Aguilar, F. (director). (2003). Paloma de papel. [DVD]. Bolivia.

Aguilera, D. (director). (1958) Dos ángeles y medio [cinta cinematográfica]. Colombia-Ecuador. Coldía.

Alcoriza, L. (director). (1973) El muro de silencio [cinta cinematográfica]. Colombia-México. Producciones Escorpión.

Amelio, G. (director). (2005). Las llaves de la casa. [DVD]. Italia.

Arango, J. (director). (2012) La playa D.C. [DVD]. Colombia. Burning Blue.

Arbeláez, C. (director). (201 I) Los colores de la montaña [DVD]. Colombia. El Bus Producciones.

Babenco, H. (director). (198I). Pixote la ley del más débil. [cinta cinematográfica]. Brasil.

Barratier. C. (director). (2004). Los coristas. [DVD]. Francia.

Boyne, J. (director). (2008). El niño con la pijama a rayas. [DVD]. Reino Unido. Briski, Z. Kauffman, R. (director). (2004) Los niños del barrio rojo. [DVD]. USA.

Buñuel, L. (director). (1950). Los olvidados. [cinta cinematográfica]. México.
Bustamante, D. (director). (2010). Andrés no quiere dormir la siesta. [DVD]. Argentina.

Carrillo, J. (director). (2011) Pequeñas voces. [DVD]. Colombia. E-nnovva, RCN Cine y Cachupedillo Cine.

Castaño, R. (director). (1986) El niño y el papa [cinta cinematográfica]. Colombia-México. Producciones Casablanca.

Coral, R. (director). (2002) Te busco [cinta cinematográfica]. Colombia. Dago García Producciones.

Dalcan, D. (director). ( 1997). Mi vida en rosa. [cinta cinematográfica]. Bélgica.

Damodaran, B. (director). (2012). Los colores del cielo. [cinta cinematográfica]. India.

Dothée, F. (director). (2013) El control [DVD]. Colombia. Dago García Producciones.

Duque, L. (director). (200I) Los niños invisibles [cinta cinematográfica]. Colombia. EGM Productions y Cinetel Ltda.

Durán, C. (director). (1977) Gamín [cinta cinematográfica]. Colombia. Producciones Cinematográficas Uno.

Favio. L. (director). (1965). Crónica de un niño solo. [cinta cinematográfica]. Argentina.

Gaviria, V. (director). (1998) La vendedora de rosas [cinta cinematográfica]. Colombia. Producciones Erwin Göggel. 
Guerra, C. (director). (2009) Los viajes del viento [DVD]. Colombia. Ciudad Lunar Producciones.

Hendrix, J. (director) .(20I2) Chocó [DVD]. Colombia. Antorcha Films.

Ladkani, R. Davidson, K. (director). (2005). El diablo de las minas. [DVD]. Bolivia.

Lizarazo, M. (director). (2008) El ángel del acordeón [DVD]. Colombia. CMO Producciones.

Loza. G. (director). (20II). La otra familia. [DVD]. México.

Lumière, L. (director). ( 1895). Repas de bébé. [cinta cinematográfica]. Francia. Luna, D. (director). (2010) Abel. [DVD]. México

Majidi, M. (director). (1999). El color del paraíso. [cinta cinematográfica]. Irak. Makhmalbaf, H. (director). (2008) Buda explotó por vergüenza. [DVD]. Irak.

Mandoki, L. (director). (2005). Voces inocentes. [DVD]. México.

Martínez, A. (director). (1927) Garras de oro - Alborada de justicia [cinta cinematográfica]. Colombia. Cali Films.

Ospina, L. Mayolo, C. (director). (1978) Agarrando pueblo. [cinta cinematográfica]. Colombia.

Padilla, P. (director). (2013) La eterna noche de las doce lunas [DVD]. Colombia. Doce Lunas Producciones.

Panahi, J. (director). (1995). El globo blanco. [cinta cinematográfica]. Irak.

Piñeyro, M. (director). (2002). Kamchatka. [DVD]. Argentina.

Rodríguez, M. Y Silva, J. (1972) Chircales [cinta cinematográfica]. Colombia. Fundación cine documental.

Rossellini. R. (director). (1948). Alemania, año cero. [cinta cinematográfica]. Italia

Ruíz, O. (director). (2010) El vuelco del cangrejo [DVD]. Colombia. Contravía Films.
Salles. W. (director). (1998). Estación central de Brasil. [cinta cinematográfica]. Brasil.

Soderguit, A. (director). (2013) Anina [DVD]. Colombia-Uruguay. Antorcha Films.

Tarkovski, A. (director). (1962). La infancia de Iván. [cinta cinematográfica]. Rusia.

Trompetero, H. (director). (2012) El paseo 2. [DVD]. Colombia. Dago García Producciones

Truffaut, F. (director). (1959). Los cuatrocientos golpes. [cinta cinematográfica]. Francia.

Vigo, J. (director). (1933). Cero en conducta. [cinta cinematográfica]. Francia.

Wood. A. (director). (2004). Machuca [DVD]. Chile.

Yimou, Z. (director). (1999). Ni uno menos. [cinta cinematográfica]. China.

\section{Material de enlace rápido ( QR)}

Actores Sociedad Colombiana de Gestión [Canal Actores S.C.G.] (2019, Octubre 31) Historia de una pelicula: "Dos ángeles y medio". Recuperado de: https://www.youtube.com/watch?v=sShq-43lc94

Anónimo. [Canal Cimavisión] (2019, Octubre 31) Cortas historias latinoamericanas - Chircales (Martha Rodríguez). Recuperado de: https://youtu. be/5MghMOFlwlc

Anónimo. [Canal John Vesques] (2019, Octubre 31) Película colombiana - La vendedora de rosas. Recuperado de: https://www.youtube.com/watch?$\mathrm{v}=\mathrm{DHLq} 5 \mathrm{Xux} \mathrm{d} \mathrm{d} 0$

Anónimo. [Canal Leyéndote .4] (2019, Octubre 31) Carmenza Duque - Tiempos de esperanza [El Papa y El Niño]. Recuperado de: https://youtu.bel KWUxiA2hd3c

Anónimo. [Canal Rayanzan] (2019, Octubre 31) Los niños invisibles tráiler. Recuperado de: https://youtu.be/OrWXtLW-Qgk 
Anónimo. [Canal Sol Okarina] (2019, Octubre 31) La eterna noche de las doce lunas - tráiler. Recuperado de: https://youtu.be/yBfOSKB3Twk

Anónimo. [Canal Yeh Haá] (2019, Octubre 31) El muro del silencio 1974. Recuperado de: https://www.youtube.com/watch?v=IS6Z5FYC8-C

Antorcha Films. [Canal Antorcha Films] (2019, Octubre 31) Chocó - tráiler oficial. Recuperado de: https://youtu.be/dw7fq_sp4jy

Cabecita Negra Producciones. [Canal Cabecitanegraproducc] (2019, Octubre 31) El resquicio tráiler. Recuperado de: https://youtu.be/J-fRUSIRuUw

Canal Zoom. [Canal Zoom] (2019, Octubre 31) InfoZoom: "Dos ángeles y medio", un testimonio del cine colombiano. Recuperado de: https://youtu. be/X-jG3e84_Iy

CMO Producciones. [Canal CMO Producciones] (2019, Octubre 31) El ángel del acordeón - tráiler. Recuperado de: https://youtu.be/vgCtfyEXB|4

Laboratorios Black Velvet. [Canal Laboratorios Black Velvet] Tráiler oficial El vuelco del cangrejo de Oscar Navia. (2019, Octubre 31). Recuperado de: https://youtu.be/OLgf-QCIEVI

Parrmur, J. [Canal Jules Parrmur] (2019, Octubre 31) Gamín - Ciro Duran. Recuperado de: https://youtu.be//4eEp2eHDVI

Proimágenes Colombia. (2019) Largometrajes. Recuperado de: http://www. proimagenescolombia.com/secciones/cine_colombiano/peliculas_colombianas/resultados_peliculas.php?nt=I

Retina Latina. [Canal Retina Latina] (2019, Octubre 31) Los colores de la montaña - tráiler. Recuperado de: https://youtu.be/TEHQ91770Ws 